\title{
Improved Arteriogenesis with Simultaneous Skeletal Muscle Repair in Ischemic Tissue by SCL+ Multipotent Adult Progenitor Cell Clones from Peripheral Blood
}

\author{
Ralf Huss $^{a}$ Matthias Heil ${ }^{b}$ Sabine Moosmann ${ }^{a}$ Tibor Ziegelhoeffer ${ }^{b}$ \\ Sabine Sagebiel ${ }^{a}$ Christian Seliger $^{a}$ Sarah Kinston $^{c}$ Berthold Gottgens ${ }^{c}$ \\ a Institute of Pathology, University of Munich, Munich, bMax Planck Institute for Physiology and Experimental \\ Medicine, Department of Experimental Cardiology, Bad Nauheim, Germany; ${ }^{\circ}$ Cambridge Institute for Medical \\ Research, Department of Haematology, Cambridge University, Cambridge, UK
}

\section{Key Words}

Adult stem cells $\cdot$ MAP-C $\cdot$ Arteriogenesis $\cdot \mathrm{SCL} \cdot$ Tissue repair

\begin{abstract}
Background: The CD34- murine stem cell line RM26 cloned from peripheral blood mononuclear cells has been shown to generate hematopoietic progeny in lethally irradiated animals. The peripheral blood-derived cell clones expresses a variety of mesodermal and erythroid/myeloid transcription factors suggesting a multipotent differentiation potential like the bone marrow-derived 'multipotent adult progenitor cells' (MAP-C). Methods: SCL+ CD34RM26 cells were transfused intravenously into mice suffering from chronic hind-limb ischemia, evaluating the effect of stem cells on collateral artery growth and simultaneous skeletal muscle repair. Results: RM26 cells are capable of differentiating in vitro into endothelial cells when cultured on the appropriate collagen matrix. Activation of the SCL stem cell enhancer (SCL+) is mediated through the binding to two Ets and one GATA site and cells start to express milieu- and growth condition-dependent levels of the endothelial markers CD31 (PECAM) and Flt-1 (VEGF-R1). Intravenously infused RM26 cells significantly
\end{abstract}

improved the collateral blood flow (arteriogenesis) and neo-angiogenesis formation in a murine hind-limb ischemia transplant model. Although transplanted RM26 cells did not integrate into the growing collateral arteries, cells were found adjacent to local arteriogenesis, but instead integrated into the ischemic skeletal muscle exclusively in the affected limb for simultaneous tissue repair. Conclusion: These data suggest that molecularly primed hem-/mesangioblast-type adult progenitor cells can circulate in the peripheral blood improving perfusion of tissues with chronic ischemia and extending beyond the vascular compartment.

Copyright @ 2004 S. Karger AG, Basel

\section{Introduction}

'Stem cell plasticity' is a controversial issue in applied biology with major implications for clinical medicine in the future. Hematopoietic stem cells (HSC) are routinely isolated from the bone marrow, peripheral blood and umbilical cord blood, either unselected or based on the expression of stem cell associated antigens, e.g. CD34. There is evidence that it is also possible to achieve hematopoietic reconstitution with large numbers of CD34-

\begin{tabular}{ll}
\hline KARGER & (c) 2004 S. Karger AG, Basel \\
1018-1172/04/0415-0422\$21.00/0 \\
$\begin{array}{l}\text { Fax +4161306 1234 } \\
\begin{array}{l}\text { E-Mail karger@karger.ch } \\
\text { www.karger.com }\end{array}\end{array}$ & $\begin{array}{l}\text { Accessible online at: } \\
\text { www.karger.com/jvr }\end{array}$
\end{tabular}

Dr. Ralf Huss

Institute of Pathology, University of Munich, Thalkirchner Strasse 36

DE-80337 Munich (Germany)

Tel +49895160 4053, Fax +498951604043

E-Mail Ralf.Huss@patho.med.uni-muenchen.de 
stem cells, which are considered to be 'adult stem cells', based on their mesenchymal co-phenotype [1]. Recent reports have suggested that adult stem cells have a considerable degree of pluripotency and plasticity, which apparently allows the generation of a variety of tissue- and organ-specific progenitors in vivo and adult stem cells are supposed to maintain a steady state of organ function after injury or disease $[2,3]$.

CD34-, stroma-like cells from the canine bone marrow can give rise to CD34+ hematopoietic precursor cells [46]. Despite in vitro evidence, the gold standard to prove any biological function is in vivo reconstitution of organs, e.g. the lympho-hematopoietic system with HSCs. We cloned the CD34- murine cell line RM26 and achieved hematopoietic recovery of syngeneic mice [7]. This progenitor cell clone does not express any lineage specific markers in vitro (lin-), but the Sca-1 antigen (Sca-1+), identifying stem cells in certain mouse strains. Immortalization with the SV40 large-T antigen did not interfere with the potential pluripotency and multilineage differentiation capability. Similarly, a cloned canine cell line from peripheral blood was also used for an autologous transplantation resulting in cells coexpressing mesenchymal markers in vitro and in vivo, e.g. osteocalcin [8]. To extend these studies to the human system, we generated a cloned equivalent from human peripheral blood cells [9]. When maintained in culture, this clonal cell line is composed of a small Rho123 low, CD34+ subpopulation and a Rho123 high, CD34- major population. Interestingly, the transcription factors GATA-1, $-2,-3$ were only expressed in the Rholow population, suggesting a commitment towards the hematopoietic lineage. By contrast, the Rhohigh major population expressed Tie-1 and VEGF mRNA. While VEGF seems to regulate HSC survival by an internal autocrine loop, the expression of the VEGF-R2 (KDR) was shown on primitive stem cells [10]. Tie-1 is also present on endothelial cells and hematopoietic progenitors [11], which draws attention to the hemangioblast as a potential pluripotent stem cell with a distinct plasticity between the hematopoietic and mesenchymal lineage. The hemangioblast, a common progenitor of blood and endothelial cells, has been identified in frog embryos as well as in mouse embryonic stem cells [12] and recently in human fetus and adult bone marrow cells $[13,14]$. Moreover, the close relationship of blood and endothelial cells is underlined by the discovery of hemogenic endothelium in mouse, chick and human embryos, where differentiated endothelial cells give rise to the HSCs of the definitive hemopoietic system [15]. Several genes have been shown to be critical regulators of both hemopoiesis and vasculogenesis (e.g. Flk-1, Tie-1, SCL, LMO-2), including the bHLH transcription factor SCL [16]. The close correlation between endothelial and $\mathrm{HSC} /$ progenitor cells is further underlined by the observation that a 640-bp enhancer has been identified $3^{\prime}$ of the mouse SCL gene, which directs expression to hemangioblasts in transgenic animals. The activity of this enhancer critically depends on three regions, which are postulated to enable the formation of a multiprotein complex containing Ets and GATA transcription factors [17].

Here we have investigated the possible relationship between the clonal RM26 cell line obtained from circulating adult cells and functional adult hemangioblast-like stem cells, which also circulate in the peripheral blood and are recruited to a site of lesion (tissue regeneration).

\section{Methods}

\section{Matrigel Assay}

Matrigel $^{\mathrm{TM}}$ was purchased from Becton-Dickinson (\# 354635) and used to coat 24-well plates following the manufacturer's instructions. RM26 cells were trypsinized and 20,000 or 40,000 cells were added per well of the coated 24-well plate. Cells were photographed after $16 \mathrm{~h}$ to monitor angiogenic activity using a Nikon inverted microscope linked to a Fuji digital camera.

\section{RT-PCR Survey}

For first strand synthesis 1-2 $\mu \mathrm{g}$ RNA from RM26 cells was dissolved in $9.7 \mu \mathrm{l}$ volume together with $2 \mu \mathrm{l}$ random hexamers $(100 \mu M$ stock, Amersham Pharmacia Biotech) and incubated at $65^{\circ} \mathrm{C}$ for $20 \mathrm{~min}$ before the samples were centrifuged for $10 \mathrm{~s}$ and placed on ice. In the second step $5 \times$ first-strand buffer (Gibco kit cat. No 28025-013) was mixed with $2 \mu 10.1 M$ DTT (1,4-dithio-DL-treitol; Sigma, Deisenhofen, Germany), $1 \mu$ l M-MLV RT, $0.8 \mu 125 \mathrm{mM}$ dNTPs (Amersham) and $0.5 \mu \mathrm{l}$ RNasin (Promega). This mixture was added to the solution from step 1 and incubated together at $37^{\circ} \mathrm{C}$ for $90 \mathrm{~min}$, then at $70^{\circ} \mathrm{C}$ for $10 \mathrm{~min}$ and finally stored at $-20^{\circ} \mathrm{C}$. The PCR reaction was performed in 0.2-milliliter thin-wall tubes with $2.5 \mu \mathrm{l}$ of $10 \times$ buffer II, $1.5 \mu 1 \mathrm{MgCl}_{2}, 0.5 \mu \mathrm{dNTPs}(10 \mu M$ stock), $0.2 \mu \mathrm{l}$ Amplitaq gold and $1 \mu \mathrm{l}$ first-strand cDNA or water (negative control) or RNA (no RT-control) in $18.3 \mu \mathrm{l}$ water. One microliter of each forward and reverse primer from the designed transcription product was added from a $25-\mu M$ stock solution. The PCR program ran for 30 cycles with an annealing temperature of $56^{\circ} \mathrm{C}$ for $30 \mathrm{~s}$ and an amplification temperature of $70^{\circ} \mathrm{C}$, also for $30 \mathrm{~s}$. The samples were then run on a $2 \%$ agarose gel. Primer sequences were available with the authors.

\section{Reporter Assay and EMSA Analysis}

Stable transfections and luciferase assays were performed as described. A total of eight independent pools of stably transfected cells were assayed for each construct. The complexity of pools was assessed by limiting dilution and found to be in excess of 50 for each electrophoration. Standard nuclear extracts were prepared and EMSA (electrophoretic mobility shift assay) was performed. 
Fig. 1. Endothelial differentiation of RM26 cells in vitro. a RM26 cells under standard growth conditions in the cell culture without any differentiation-inductive matrix (original magnification, $\times 100$ ). b RM26 cells grown on an angiogenic-inductive matrix (Matrigel assay) forming extensive networks indicative of endothelial cells (original magnification, $\times 50)$.
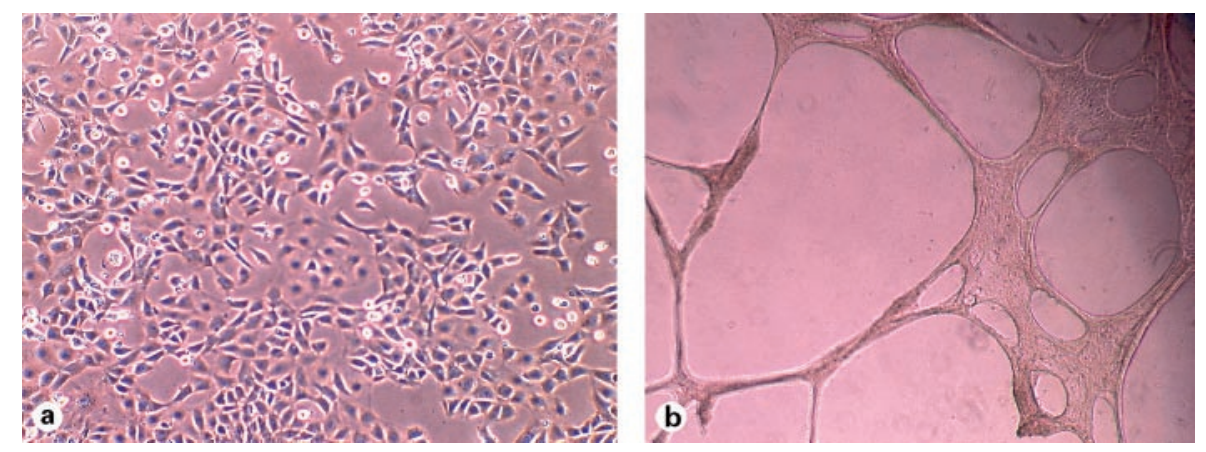

Flow Cytometry of RM26 Cells

RM26 cells were cultured without serum or in the presence of $10 \%$ fetal calf serum (FCS) (purchased from PAN-Biotech GmbH, Germany) for $24 \mathrm{~h}$ until $80 \%$ cell density or complete confluency. RM26 cells were trypsinized, thoroughly washed at least three times in phosphate-buffered saline (PBS) and stained with directly labeled antibodies against CD31 (PE labeled), CD34 (FITC labeled) and VEGF-R1 (PE labeled) (purchased from Becton-Dickinson, Heidelberg, Germany) for 30 min in FACS buffer (PBS, 2\% FCS, $0.05 \%$ Na-Azid). Cells were washed afterwards in FACS buffer and finally resuspended in $300 \mu \mathrm{l}$ FACS buffer. 100,000 cells of each sample were used for analysis by flow cytometry (FACScan, Becton Dickinson, Cellquest Software).

\section{Transplantation of RM26 Cells into Host Animals}

The capability of RM26 cells to stimulate collateral artery growth was tested in a mouse peripheral artery disease model as previously described [18]. In brief, the right femoral artery of anaesthetized $\mathrm{Balb} / \mathrm{c}$ mice was exposed and ligated distal to the arteria profunda femoris. RM26 cells $\left(0.5 \times 10^{6} /\right.$ mouse $)$ were labeled with the PKH2 green fluorescent cell linker kit (Sigma, Deisenhofen, FRG) according to the manufacturer's instructions and were injected into a tail vein directly after operation. To characterize the perfusion recovery in this chronic ischemia model, relative blood flow was measured in the footpad before, directly after ligation, and on postoperative days 7, 14 and 21 using a laser Doppler imager [18]. Finally, for tissue harvesting mice were heparinized and euthanized. After the preparation and cannulation of the aorta, tissue was perfused for $5 \mathrm{~min}$ with PBS containing $0.1 \%$ adenosine to achieve maximal vasodilatation, followed by 20 min perfusion with pFA ( $2 \%$ in PBS) and the adductor and gastrocnemius muscles were sampled.

\section{Immune Histochemistry}

Collateral artery formation during arteriogenesis was visualized by the immunostaining of smooth muscle cells in the vessel wall with an antibody against $\alpha$-smooth muscle actin (HHF). The mouse tissue from the adductor region containing the growing collateral arteries was excised from the animals and initially frozen in TissueTec ${ }^{\circledR}$ and later fixed in $4 \%$ paraformaldehyde prior to paraffin embedding. 0.5 - $\mu \mathrm{m}$-thick sections were sliced from the paraffin block and slides were deparaffinized in xylene and dried in ethanol. Endogenous peroxidase activity was blocked by $3 \% \mathrm{H}_{2} \mathrm{O}_{2}$. Antigen retrieval was performed by placing the slides in a coplin jar containing citrate buffer and heating the jar in a microwave oven $(700 \mathrm{~W})$ to $95^{\circ} \mathrm{C}$ for $15 \mathrm{~min}$.
Smooth muscle actin was stained with an anti- $\alpha$-HHF antibody (Roche, Germany; \# 1148818). Specific staining was detected with a secondary IgG/Biotin F(ab) 2 (Dako, Hamburg, Germany; E0413) and visualized in AEC-solution (Dako).

To visualize the transplanted cells in different tissues after formalin fixation and paraffin embedding, we used an indirect immunoperoxidase method (Picture PLUS Kit, Zymed, San Francisco, Calif., USA). Endogenous peroxidase activity was also blocked by $3 \% \mathrm{H}_{2} \mathrm{O}_{2}$. Transplanted cells were finally detected by an unconjugated primary monoclonal mouse anti-SV40 antibody (Oncogene Research Products, Boston, Mass., USA). Optimum labeling of SV40 staining was obtained after microwave pretreatment [two cycles of 15 min in Target Retrieval Solution (Dako)]. SV40 peroxidase activity was detected by the addition of the Vector VIP substrate kit (Vector Laboratories, Burlingame, Calif., USA).

Immunohistochemical staining for myoglobin (staining skeletal and cardiac muscle) was achieved with a polyclonal myoglobin antibody (Dako). Sections were incubated for $1 \mathrm{~h}$ at room temperature diluted in DakoCytomation Antibody Diluent with Backround Reducing Components (Dako). Myogenin was detected by Liquid AEC Chromogene Kit (BioGenex, San Ramon, Calif., USA). The sections were then counterstained with hematoxylin.

\section{Results}

\section{Matrix-Induced Differentiation with Endothelial Phenotype}

RM26 cells were derived from peripheral blood mononuclear cells. When cultured, RM26 cells display a fibroblast-like morphology, while transplanted RM26 cells were able to generate hematopoiesis in the appropriate in vivo model. Here, we assessed the endothelial differentiation potential of RM26 cells using the matrigel assay. RM26 cells readily formed extensive networks (fig. 1), a phenotype typically associated with endothelial cells. Endothelial networks were established after only $12 \mathrm{~h}$, suggesting that at least a substantial proportion of RM26 cells have an angioblast/hemangioblast phenotype when maintained in culture. 
Gene Expression Profile of the Murine Adult Stem Cell Clone RM26

Next, we performed an extensive gene expression survey of RM26 cells to assess whether the apparent bi-potential differentiation capacity to both hematopoietic and endothelial lineages was reflected in the gene expression pattern for those two differentiation processes. This comprehensive analysis demonstrated that RM26 cells expressed markers for both hematopoietic and endothelial cells (table 1) as well as some primitive mesodermal markers and a large number of genes known to be coexpressed on endothelial and hematopoietic progenitor cells. This observation is consistent with a model suggesting that, when grown in culture, subpopulations of RM26 cells differentiate down the hematopoietic and endothelial lineages.

\section{The SCL Stem Cell Core Enhancer Is Active in RM26 Cells}

We investigated whether the SCL stem cell core enhancer was also active in RM26 cells. As shown in figure 2, the 640-bp stem cell enhancer fragment was active in stable transfection assays giving approximately 4-fold higher activity than the minimal promoter control (compare SV/luc/SH0.6 with SV/luc). Moreover, analysis of mutant enhancer fragments demonstrated that mutations in the regions 1-3 each individually reduced the enhancer activity between 2- and 4-fold. Regions 1 and 2 contain Ets factor consensus-binding sites, while region 3 contains a GATA factor-binding site. Each individual motif is critical for enhancer activity in hemangioblasts. The data presented here suggest that the activity of the SCL stem cell enhancer in RM26 critically depended on Ets and GATA factors binding to regions 1,2 and 3 . Given the fact that there is also a Myb consensus-binding site in region 1, we wanted to confirm the role of Ets factors in regulating stem cell enhancer activity in RM26. We performed electrophoretic mobility shift assays using RM26 nuclear extracts and radiolabeled oligonucleotides corresponding to regions 1 and 2. One specific complex was identified binding to region 1 . Competition experiments using oligonucleotides with specific mutations in only the Myb site (1m oligomer) or only the Ets site (1e oligomer) demonstrated that this complex bound to the GGAT ets consensus site. Band shift analysis with the region 2 oligo identified three major complexes (fig. 3, compare lanes 1-3). However, only one of these was not competed by the mutant oligo carrying the exact mutation that gave rise to the reduced enhancer activity in transfection assays. This complex was, therefore, likely to correspond to an Ets factor binding to the GGAA Ets consensus site.
Table 1. RT-PCR survey of RM-26 gene expression

\begin{tabular}{|c|c|c|c|}
\hline & & RM26 & E11.5 \\
\hline \multirow[t]{4}{*}{ Mesodermal markers } & HPRT & $\mathrm{Y}$ & $\mathrm{Y}$ \\
\hline & BMP RIA & $\mathrm{Y}$ & $\mathrm{Y}$ \\
\hline & BMP-4 & $\mathrm{Y}$ & $\mathrm{Y}$ \\
\hline & Smad1 & Y & $\mathrm{Y}$ \\
\hline \multirow[t]{9}{*}{ Erythroid/myeloid genes } & $\zeta$ globin & $\mathrm{Y}$ & $\mathrm{Y}$ \\
\hline & $\alpha$ globin & $\mathrm{Y}$ & $\mathrm{Y}$ \\
\hline & $\beta \mathrm{H} 1$ globin & $\mathrm{N}$ & $\mathrm{Y}$ \\
\hline & $\varepsilon \gamma 2$ globin & $\mathrm{N}$ & $\mathrm{Y}$ \\
\hline & $\beta$ major globin & $\mathrm{N}$ & Y \\
\hline & MPO & $\mathrm{N}$ & $\mathrm{Y}$ \\
\hline & Lysozyme & $\mathrm{Y}$ & $\mathrm{Y}$ \\
\hline & $v a v$ & $\mathrm{~N}$ & $\mathrm{Y}$ \\
\hline & Epo R & $\mathrm{Y}$ & $\mathrm{Y}$ \\
\hline \multirow{21}{*}{ Transcription factors } & Scl & $\mathrm{Y}$ & $\mathrm{Y}$ \\
\hline & GATA-1 & $\mathrm{N}$ & $\mathrm{Y}$ \\
\hline & GATA-2 & $\mathrm{Y}$ & $\mathrm{Y}$ \\
\hline & GATA-3 & $\mathrm{Y}$ & $\mathrm{Y}$ \\
\hline & GATA-4 & $\mathrm{N}$ & $\mathrm{N}$ \\
\hline & GATA-5 & $\mathrm{Y}$ & $\mathrm{Y}$ \\
\hline & GATA-6 & $\mathrm{Y}$ & $\mathrm{Y}$ \\
\hline & PU.1 & $\mathrm{N}$ & $\mathrm{Y}$ \\
\hline & EKLF & $\mathrm{Y}$ & $\mathrm{Y}$ \\
\hline & c-myb & $\mathrm{Y}$ & $\mathrm{Y}$ \\
\hline & $\mathrm{LMO} 2$ & $\mathrm{Y}$ & $\mathrm{Y}$ \\
\hline & Ets1 & Y & Y \\
\hline & Ets2 & $\mathrm{Y}$ & $\mathrm{Y}$ \\
\hline & Fli1 & $\mathrm{Y}$ & $\mathrm{Y}$ \\
\hline & Erg & $\mathrm{N}$ & $\mathrm{Y}$ \\
\hline & Elf-1 & $\mathrm{Y}$ & $\mathrm{Y}$ \\
\hline & Tel & $\mathrm{Y}$ & $\mathrm{Y}$ \\
\hline & Elk1 & $\mathrm{N}$ & $\mathrm{Y}$ \\
\hline & ERM & $\mathrm{N}$ & $\mathrm{Y}$ \\
\hline & Elf-2 & $\mathrm{N}$ & Y \\
\hline & Elf-3 & $\mathrm{N}$ & $\mathrm{Y}$ \\
\hline \multirow[t]{10}{*}{ Endothelial markers } & VEGF-R & $\mathrm{Y}$ & $\mathrm{Y}$ \\
\hline & Flk-2/Flt3 & $\mathrm{N}$ & $\mathrm{N}$ \\
\hline & CD31 & $\mathrm{Y}$ & $\mathrm{Y}$ \\
\hline & Tie-1 & $\mathrm{N}$ & $\mathrm{Y}$ \\
\hline & Tie-2 & $\mathrm{Y}$ & $\mathrm{Y}$ \\
\hline & Flt-1 & $\mathrm{N}$ & $\mathrm{N}$ \\
\hline & Thrombomodulin & $\mathrm{Y}$ & $\mathrm{Y}$ \\
\hline & VE-cadherin & $\mathrm{Y}$ & $\mathrm{Y}$ \\
\hline & vWF & $\mathrm{Y}$ & $\mathrm{Y}$ \\
\hline & VEGF & $\mathrm{Y}$ & $\mathrm{Y}$ \\
\hline \multirow[t]{2}{*}{ HSC markers } & CD34 & $\mathrm{Y}$ & $\mathrm{Y}$ \\
\hline & c-kit & $\mathrm{Y}$ & $\mathrm{Y}$ \\
\hline
\end{tabular}

Total RNA was prepared from RM26 and whole fetal mouse cells (E11.5) and analyzed by RT-PCR. Monoclonal RM26 cells seem to be more immature and less committed to hematopoiesis/myelopoiesis than the entire E11.5 population. The degree of general transcriptional activity is also lower in the predominantly quiescent CD34population, but with the potential of endothelial precursor cells. 
Fig. 2. Active SCL stem cell core enhancer in RM26 cells. The top part of the figure illustrates the location of the +19 core enhancer $3^{\prime}$ of the mouse SCL locus together with a human/mouse alignment indicating the three conserved sequence blocks with Ets, Ets and GATA family transcription factor-binding sites (regions 1-3). The lower part summarizes the results from luciferase reporter gene studies showing that the +19 core enhancer (SV/luc/SH0.6) is approximately 4-fold more active than the minimal promotor control plasmid (SV/luc). Moreover, mutations in regions 1-3 all significantly inhibited enhancer activity (see SV/ luc/SH0.6mut; 1-3).
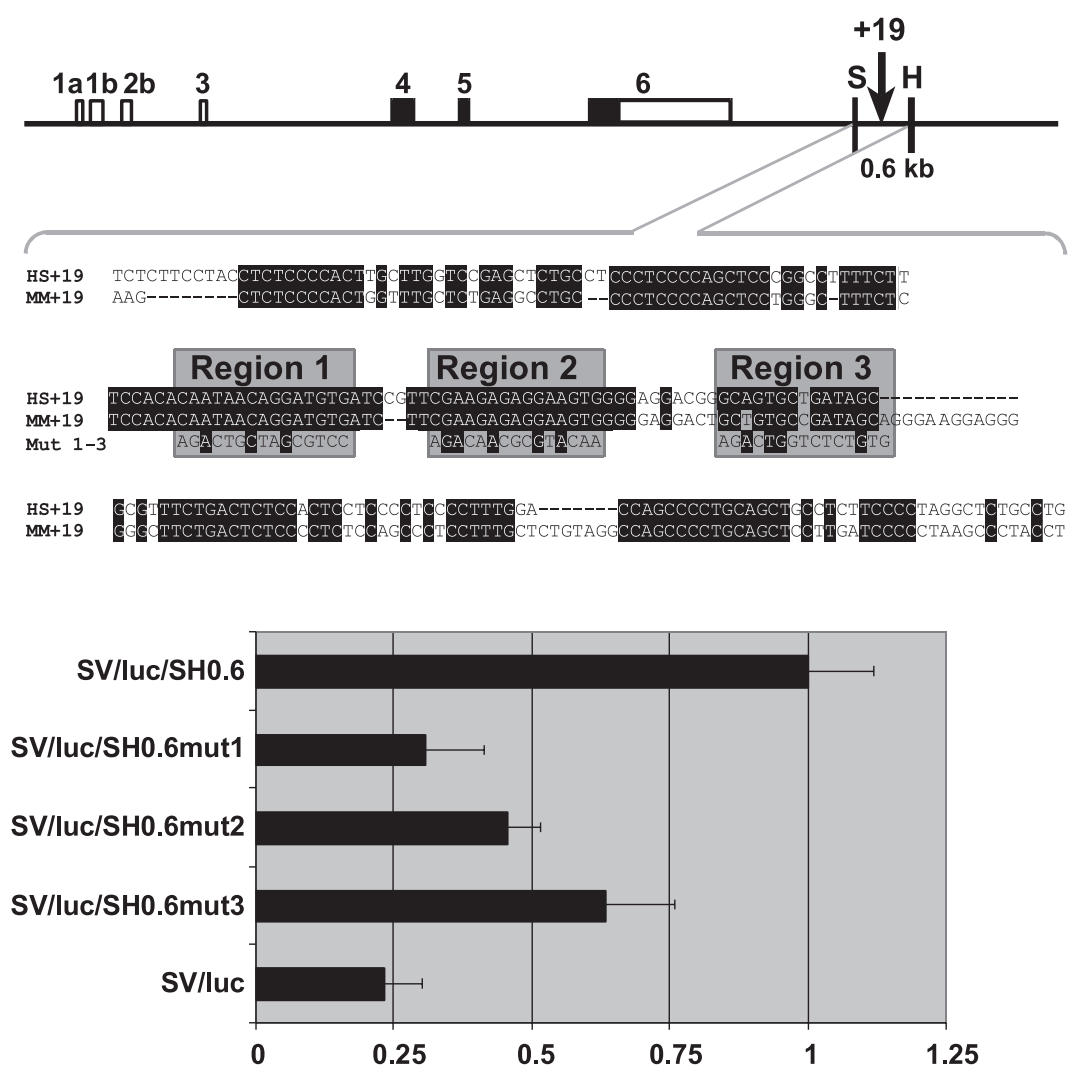

\section{Surface Expression of Endothelial Markers}

RM26 cells were analyzed for the expression of different endothelial surface markers such as CD31 (PECAM), CD34 and VEGF-R1 without or in the presence of 10\% FCS for 1, 24 and $48 \mathrm{~h}$. In the presence of serum, RM26 cells showed a strong spontaneous expression of different endothelial markers after $24 \mathrm{~h}$ (fig. 4), while only few RM26 cells expressed CD31, CD34 or VEGF-R1 in the absence of FCS. RM26 cells seize to grow in cell culture after serum starvation or when grown at low plating density.

Fig. 3. Ets-family transcription factors bind to regions 1 and 2 in RM26 cells. Electrophoretic mobility shift assays using a radiolabeled oligo for region 1. a Single complex (I) was identified, binding of which was competed by excess w.t. (wild-type) or myb-mutant oligos $(1 \mathrm{~m})$, but not by excess Ets mutant oligomers (1e). b Electrophoretic mobility shift assays using a radiolabeled oligo for region 2 . Three complexes were bound and competed by excess w.t. oligos. Only complex II, however, was specific for the mutation used in the functional studies as it was not competed by excess mutant oligomers (2). a

Region 1

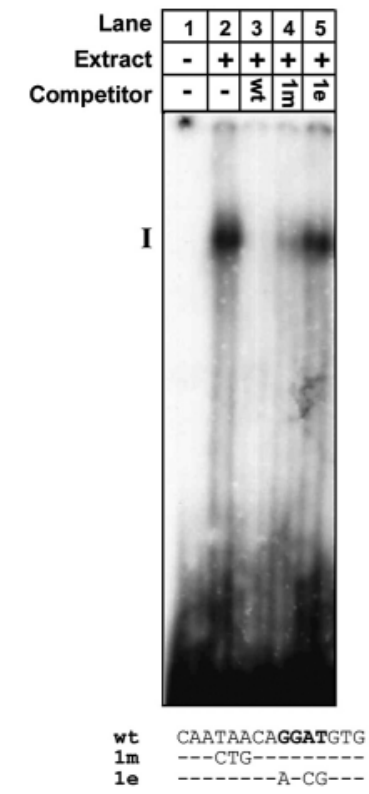

b Region 2

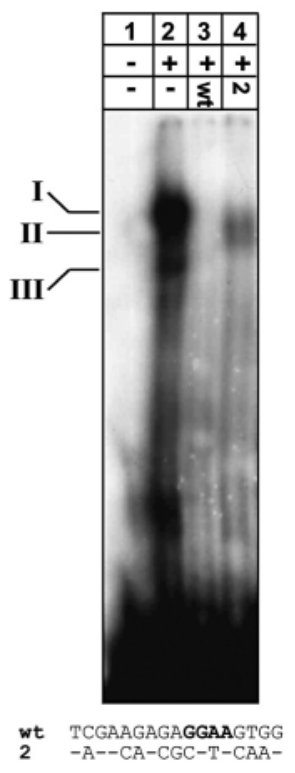


Fig. 4. Expression of endothelial-associated proteins on RM26 cells. RM26 cells express moderate levels of CD34 and CD31 (a) and VEGF-R1 (b) grown in culture for $24 \mathrm{~h}$ at intermediate cell density without serum. In the presence of serum, CD31 expression (c) and VEGF-R1 expression (d) increase significantly, suggesting a more angiogenic environment.

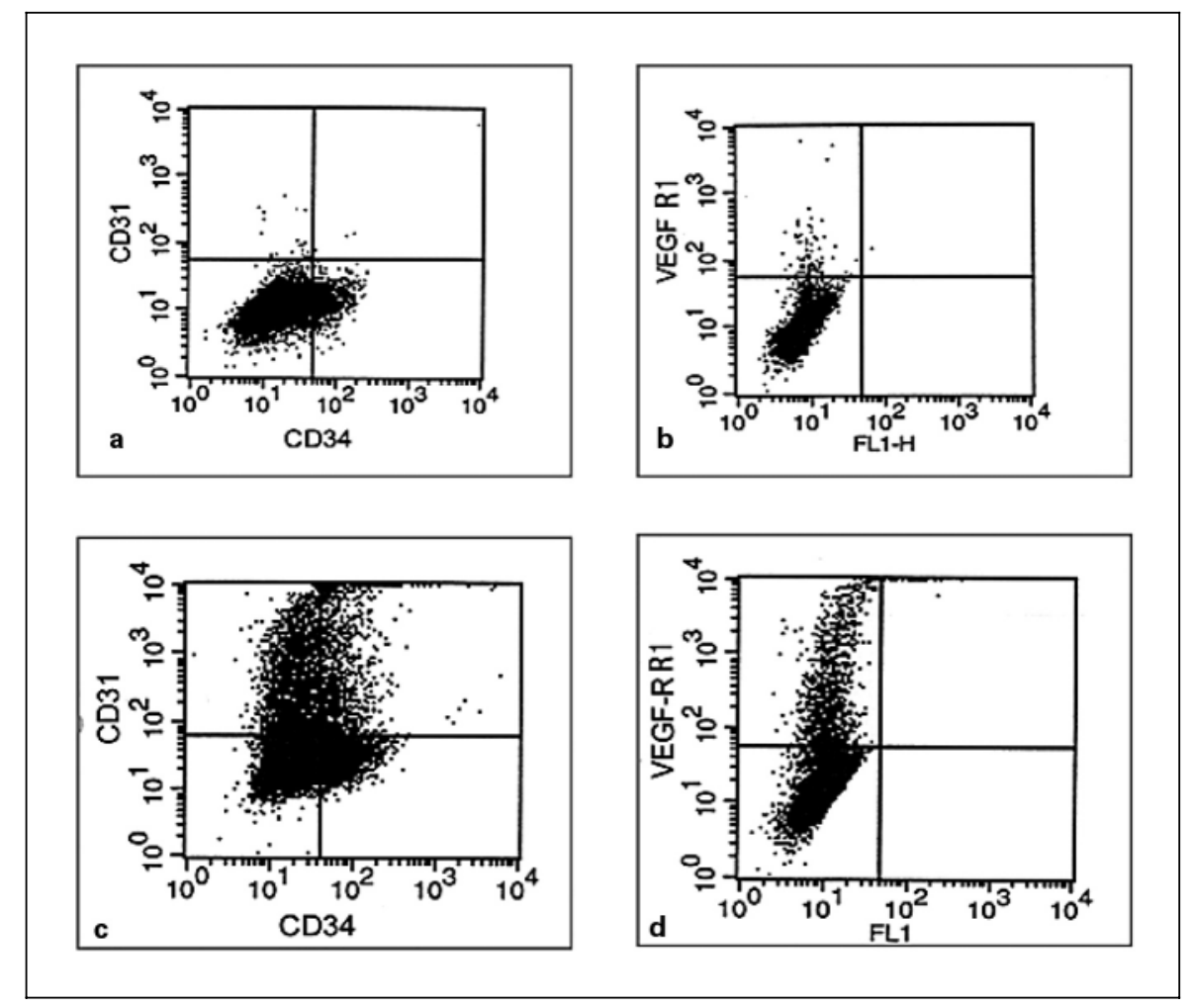

Effects of RM26 Cells on Collateral Blood Flow

RM26 cells were injected via the tail vein into mice directly after ligation of the right femoral artery. Blood perfusion of the mouse hind-limb after femoral artery ligation was then assessed before, immediately after operation and on postoperative days 7, 14, and 21 by laser Doppler imaging in mice injected with RM26 cells and in control animals. Blood flow ratio (right vs. left; R/L) decreased in both groups $(n=6)$ immediately after ligation of the femoral artery $[0.17 \pm 0.02$ (control) vs. 0.15 \pm 0.02 (RM26)]. On day 7, blood flow in the RM26treated group was significantly improved when compared to controls $(0.52 \pm 0.07$ vs. $0.66 \pm 0.07)$. This difference continued to increase during the observation period (fig. 5a). However, accelerated formation of large collateral vessels (improved arteriogenesis) was observed histomorphologically, particularly in the adductor muscles, only in the operated limb, which had been exposed to high shear forces due to the redirected blood flow after occlusion of the femoral artery (fig. 5b). Semi-quantitative analysis of arterial vessel size and vessel density revealed an approximate $20 \%$ improvement of both parameters in mice that received a stem cell transplantation. Fluorescent or SV40(+) RM26 cells could not be detected as an integrated part of these differentiated collaterals, but clusters of SV40(+) cells were found adjacent to arteriogenesis (fig. 5c, d). The infusion of stem cells 1 day later after arterial ligation had no effect on arteriogenesis.

\section{Integration of RM26 Cells in Skeletal Muscle}

Prior to infusion, RM26 cells were labeled with the green fluorescent dye PKH2. The gastrocnemii muscles of both limbs were harvested after termination of the experiment and sections of the muscles were analyzed by conventional and fluorescence microscopy also after additional immunohistochemistry. As figure 6a shows, isolated green fluorescent cells were found integrated into the skeletal muscle at the affected limb, while transplanted stem cells could also not be detected in other muscular tissue, i.e. in the contralateral limb or other parenchymal organs. Conventional serial sections revealed a regular striated muscular differentiation only with signs of atrophy, but with enlarged vessels in the vicinity (fig. 6b). Regular striated muscle differentiation in the areas with transplanted green cells was demonstrated by regular myoglobin staining (fig. 6c) and SV40(+) nuclei could be detected and localized in the gastrocnemius muscle of the affected limb (fig. 6d). 

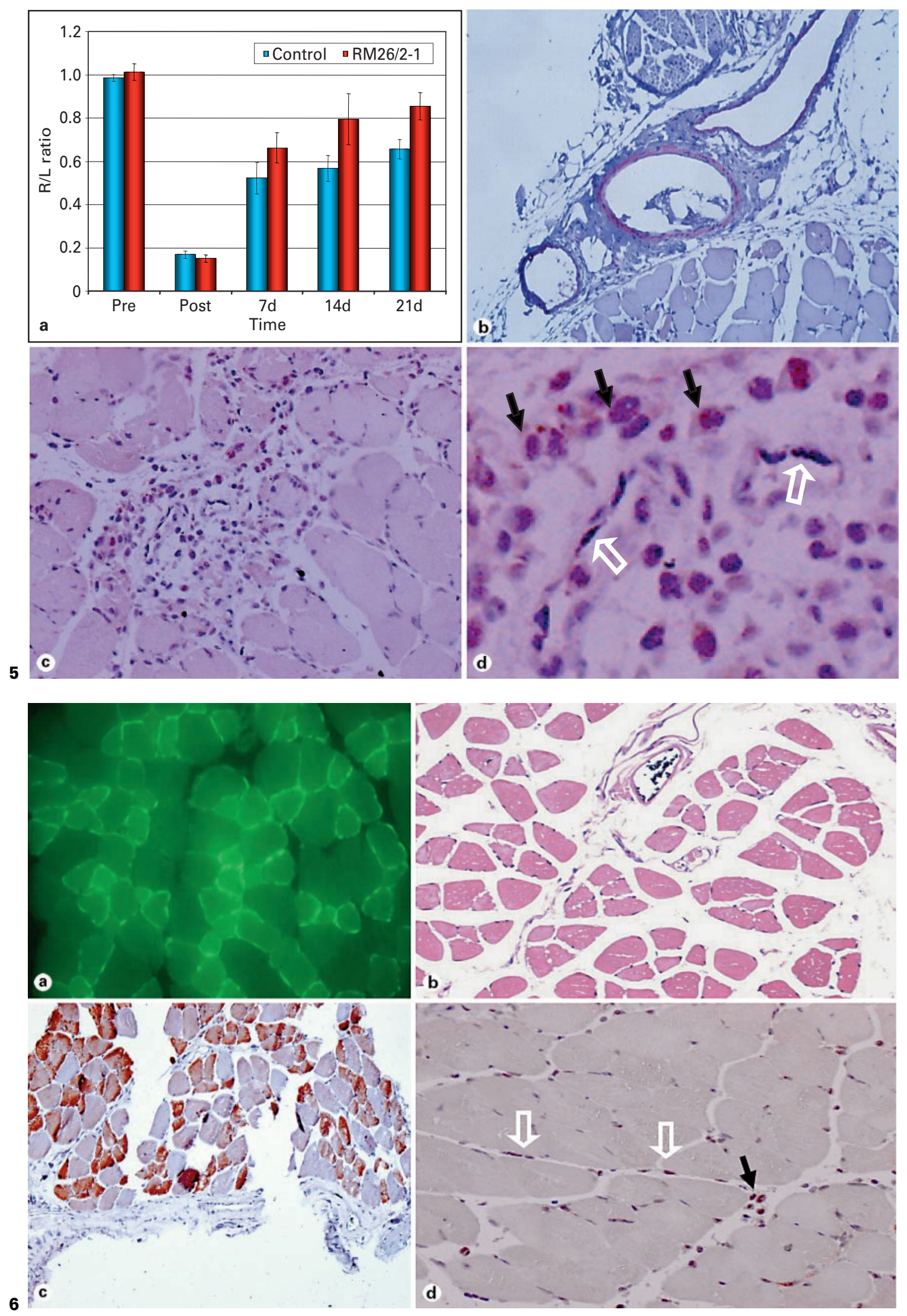


\section{Discussion}

The degree of plasticity of adult stem cells is still a matter of much controversy. However, there is evidence of the differentiation potential of CD34- stem cells like RM26 cells into various mesenchymal tissues [3], including differentiation into endothelial cells during neo-angiogenesis [20,21]. Since the expression of the bHLH transcription factor SCL amplifies the numbers of hemangioblasts during embryonic development [22], and we observed that this key regulator of endothelial and hemangioblast function was indeed expressed in RM26 cells, this cell population may represent functional hemangioblasts.

Although mesenchymal stem cells are routinely isolated from bone marrow [23], RM26 cells were generated from the peripheral blood [7, 24].

Fig. 5. Transplanted RM26 cells improve relative blood flow in affected limb. a Blood flow ratio (R/L) in hind-limbs from mice without treatment (blue bars) or after transplantation with RM26 cells (red bars) as assessed by laser Doppler imaging postoperatively and 7, 14 and 21 days after femoral artery ligation. Mice that received stem cell transplantation showed an improved relative blood flow in the affected limb as a measure of accelerated collateral vessel formation. b Serial sections of the adductor muscle region in the ligated limb show enlarged and growing vasculature with mild inflammation and adjacent cells in the connective tissue (HHF staining; original magnification, $\times 25$ ). Semi-quantitative analysis of vessel size and density revealed an approximately $20 \%$ improvement of both parameters in mice that received a stem cell transplantation compared to mice with chronic ischemia without additional stem cell treatment. c Detection of SV40(+) nuclei (red) in cells adjacent to the growing vasculature without evidence of RM26 cells incorporated into the vessel walls (original magnification, $\times 200$ ). d Magnification of c, showing unstained endothelial cells (dark violet nuclei) in two small capillary vessels (open arrows) without integration of the SV40(+) cells or pericytes (closed arrows) (original magnification, $\times 400$ ).

Fig. 6. Integration of transplanted cells in striated skeletal muscle. a Serial sections through the skeletal muscle of the m. gastrocnemius in the affected limb show fluorescence-labeled striated muscle cells, suggesting an integration of transplanted and PKH-2-stained RM26 cells into the ischemic and regenerating muscle already 3 days after transplantation (original magnification, $\times 200$ ). b Conventional serial sections of a revealed a regular striated muscular differentiation with signs of mild atrophy, but with enlarged vessels in the close proximity (HE; original magnification, $\times 200$ ). c Myoglobin staining of serial sections from areas with $\mathrm{PKH}-2(+)$ muscle cells (original magnification, $\times 100)$. d Detection of SV40(+) nuclei from transplanted RM26 cells in regenerating skeletal muscle (original magnification, $\times 400)$. Open arrows show stained nuclei of the adjacent striated muscle.
The Angiogenic Potential of CD34-Stem Cells

Similar to the results obtained in the human stem cells [9], RM26 cells also express a variety of mesodermal and erythroid/myeloid transcription factors, including SCL, GATA-2, $-3,-5$ and -6 , but also the endothelial markers flt-1, PECAM-1 and Tie-1 (table 1). The expression of these surrogate endothelial markers, e.g. PECAM-1 and Flt-1 (VEGF-R1), is particularly high when the growth conditions are favorable in vitro. Given the ease of endothelial differentiation and tube activity in the matrigel assay, the expression of endothelial marker genes and most importantly the strong upregulation of those genes in actively growing cultures, RM26 cells may indeed be thought of as endothelial precursor cells. However, the functional angiogenic properties of this murine stem cell clone had to be proven ultimately in the appropriate in vivo model of chronic hypoxia, as used in this study (fig. 5a). Yolk sac-derived cell lines express SCL just as RM26 cells. SCL is the key regulator of hemangioblast formation [22] and the expression of SCL in hemangioblasts is mediated by a $3^{\prime}$ enhancer, also termed the SCL stem cell enhancer $[17,25]$, which was also found to be active in RM26 cells. The studies presented here suggest that activity of the SCL stem cell enhancer may be used as a surrogate marker for the evaluation of hemangioblast cell line models, while the hemangioblast (and RM26 cells) may be a common progenitor of hematopoietic and endothelial cells [26].

\section{Milieu-Dependent Differentiation in vivo}

Collateral artery growth (arteriogenesis) has been shown to be a potent adaptive blood vessel growth in adult organisms to achieve sufficient blood flow recovery after the occlusion of a major artery [27]. It has been shown that recruitment of circulating blood cells, namely monocytes, contributes to the enlargement of pre-existent collateral anastomoses to true arteries by the augmentation of cells integrated in the vessel wall [18]. In contrast, we were not able to identify RM 26 cells integrated into the growing collateral artery. Instead a number of cells adjacent to the improved arteriogenesis showed SV40(+) nuclei as a sign of their RM26 origin. From this result we concluded that collateral artery growth in this model may not necessarily require the integration of circulating cells but may rather be accomplished through proliferation of the cells present in the pre-existent collateral arteriole. The role of the RM26 cells may be supportive e.g. by releasing stimulating and activating cytokines and growth factors, which in turn then participate in creating an inflammatory environment which is necessary for the 
enhancement of arteriogenesis. It was suggested that stem cells reside as nonproliferating perivascular pericytes or supporting cells adjacent to the growing vasculature, releasing growth factors and stimulating the differentiation and possibly proliferation of pre-existing angiogenic progenitors $[28,29]$. Such a growth factor candidate could be the placental growth factor $(\mathrm{PlGF})$, which is able to recruit pre-existing and primed stem cells from other reservoirs like the bone marrow [30], and is able to directly stimulate arteriogenesis [31, 32]. Similar results were reported in a recent study where implantation of bulk peripheral blood mononuclear cells into ischemic hibernating myocardium resulted in a significant reduction of the ischemic area and the formation of new collateral blood vessels without incorporation of the implanted cells into the newly formed capillaries [33]. It was also reported recently that bone marrow-derived stem cells provide functional hemangioblast activity in vivo [21] or tune the appropriate arteriogenesis at the site of lesion [22]. Consistent with this is the observation that impaired recruitment of bone marrow-derived stem cells interferes with successful angiogenesis [33]. This is in contrast to the study by Iba et al. [34], who injected peripheral blood-derived monocytes along with platelets directly into the ischemic limb. Also Ziegelhoeffer et al. [28] reported recently that bone marrow-derived cells do not incorporate into adult growing vasculature, unless they become part of tumor neoangiogenesis [28].

\section{The Hemangioblast as a Stem Cell for Tissue \\ Regeneration and Organ Maintenance?}

The SCL stem cell enhancer is active in the murine stem cell line RM26, requiring the same Ets and GATA sites implicated in the amplification of hemangioblasts and initiation of angiogenic differentiation [17]. Although the majority of stem cells in the bone marrow are quiescent and refractory to external signals [35], Jiang et al. [36] propose that multipotent adult progenitors cells or MAPCs from the bone marrow are the most potent mesenchymal stem cells. Soluble factors, like PIGF and other angio-inductive factors, are also secreted by otherwise quiescent bone marrow stromal cells and tissue fibroblasts, depending on secondary signals and the local milieu.

Although we also did not show any integration of transplanted RM26 stem cells in our model despite growing vasculature at the site of lesion and ischemia, Harraz et al. [37] have shown that a subset of adult peripheral blood leukocytes can integrate into the endothelium of blood vessels. However, this incorporation requires the coinjection with CD34+ stem cells, indicating that leukocyte-leukocyte (CD34-/CD34+) interactions are necessary for the successful execution of the angiogenic program in vivo.

The principle of neovascularization via progenitor or stem cells has been reported before. In the present study, we found that RM26 cells are capable of inducing angiogenesis in vitro and improve hind-limb perfusion in vivo. Moreover, evidence of an intramuscular integration might indicate a pleiotropic effect of RM26 in ischemic muscles, extending beyond the vascular compartment. Further studies are required to characterize the functional relevance of the myocyte substitution capacity of RM26 cells.

\section{References}

1 Thalmeier K, Meissner P, Moosmann S, et al: Mesenchymal differentiation and organ distribution of established human stromal cell lines in NOD/SCID mice. Acta Haematol 2001;105: 150-165.

2 Horwitz EM, Prockop DJ, Fitzpatrick LA, et al: Transplantability and therapeutic effects of bone marrow-derived mesenchymal cells in children with osteogenesis imperfecta. Nat Med 1999;5:111-116.

3 Pittinger MF, Mackay AM, Beck, SC, et al: Multilineage potential of adult human mesenchymal stem cells. Science 1999;276:318-321.

4 Huss R, Hong DS, McSweeney PA, et al: Differentiation of canine marrow cells with hematopoietic characteristics from an adherent stromal cell precursor. Proc Natl Acad Sci USA 1995;92:748-752.
5 Huss R: CD34-negative stem cells as the earliest precursors of hematopoietic progeny. Exp Hematol 1998;26:1022-1023.

6 Zanjani ED, Almeida-Porada G, Livingston AG, et al: Human bone marrow CD34-negative cells engraft in vivo and undergo multilineage expression that includes giving rise to CD34+ cells. Exp Hematol 1998;26:353-358.

7 Lange C, Kaltz C, Thalmeier K, et al: Longterm hematopoietic reconstitution of syngeneic mice with a peripheral blood-derived, monoclonal CD34-, Sca-1+, Thy-1 low, c-kit+ stem cell line. J Hematotherapy Stem Cell Res 1999; $8: 335-342$
8 Huss R, Lange C, Weissinger EM, et al: Evidence of peripheral blood-derived, plastic adherent CD34-/low hematopoietic stem cell clones with mesenchymal stem cell characteristics. Stem Cells 2000;18:252-260.

9 Conrad C, Göttgens B, Kinston S, et al: GATAtranscription in a small Rhodamine 123 (low) CD34(+) subpopulation of a peripheral bloodderived CD34(-) CD105(+) mesenchymal cell line. Exp Hematol 2002;30:887-895.

10 Ziegler BL, Valtieri M, Porada GA, et al: KDR receptor: A key marker defining hematopoietic stem cells. Science 1999;285:1553-1558.

11 Yano M, Iwama A, Nishio H, et al: Expression and function of murine receptor tyrosine kinases, TIE and TEK, in hematopoietic stem cells. Blood 1997;89:4317-4326. 
12 Shalaby F, Rossant J, Yamaguchi TP, Gertsenstein M, et al: Failure of blood-island formation and vasculogenesis in Flk-1-deficient mice. Nature 1995:376:62-66.

13 Peault B, Oberlin E, Tavian M: Emergence of hematopoietic stem cells in the human embryo. CR Biol 2002;325:1021-1026.

14 Pelosi E, Valtieri M, Coppola S, et al: Identification of the hemangioblast in postnatal life. Blood 2002; 100:3203-3208.

15 Oberlin E, Tavian M, Blazsek I, et al: Bloodforming potential of vascular endothelium in the human embryo. Development 2002;129: 4147-4157.

16 Begley CG, Green AR: The SCL gene: From case report to critical hematopoietic regulator. Blood 1999;93:2760-2770.

17 Göttgens B, Nastos A, Kinston S, et al: Establishing the transcriptional programme for blood: The SCL stem cell enhancer is regulated by a multiprotein complex containing Ets and GATA factors. EMBO J 2002;21:1-12.

18 Heil M, Ziegelhoeffer T, Pipp F, et al: Blood monocyte concentration is critical for enhancement of collateral artery growth. Am J Physiol Heart Circ Physiol 2002;283:H2411-H2419.

19 Reyes M, Lund T, Lenvik T, et al: Purification and ex vivo expansion of postnatal human marrow mesodermal progenitor cells. Blood 2001;98:2615-2625.

20 Grant MB, May WS, Cabalerro S, et al: Adult hematopoietic stem cells provide functional hemangioblast activity during retinal neovascularization. Nat Med 2002;8:607-612.
21 Otani A, Kinder K, Ealt K, et al: Bone marrowderived stem cells target retinal astrocytes and can promote or inhibit retinal angiogenesis. Nat Med 2002;8:1004-1010.

22 Gering M, Rodaway AR, Gottgens B, et al: The SCL gene specifies haemangioblast development from early mesoderm. EMBO J 1998;17: 4029-4045.

23 Huss R: Isolation of primary and immortalized CD34- hematopoietic and mesenchymal stem cells from various sources. Stem Cells 2000;18: $1-9$.

24 Huss R, Günther W, Schumm M, et al: CD34negative hematopoietic stem cells isolated from human peripheral blood cells as ultimate precursors of hematopoietic progenitors. Infusionsther Transfusionsmed 1997;24:404-409.

25 Sanchez M, Gottgens B, Sinclair AM, et al: An SCL 3' enhancer targets developing endothelium together with embryonic and adult haematopoietic progenitors. Development 1999; 126:3891-3904.

26 Choi K: The hemangioblast: A common progenitor of hematopoietic and endothelial cells. J Hematother Stem Cell Res 2002;11:91-101.

27 Scholz D, Cai WJ, Schaper W: Arteriogenesis, a new concept of vascular adaptation in occlusive disease. Angiogenesis 2001;4:247-257.

28 Ziegelhoeffer T, Fernandez B, Kostin S, et al: Bone marrow-derived cells do not incorporate into the adult growing vasculature. Circ Res 2004;94:230-238.

29 Scholz D, Ziegelhoeffer T, Helisch A, et al: Contribution of arteriogenesis and angiogenesis to postocclusive hindlimb perfusion in mice. J Mol Cell Cardiol 2002;34:775-787.
30 Hattori K, Heissig B, Wu Y, et al: Placental growth factor reconstitutes hematopoiesis by recruiting VEGFR1+ stem cells from bonemarrow microenvironment. Nat Med 2002;8: 841-849.

31 Pipp F, Heil M, Issbruckner K, et al: VEGF-1 Selective VEGF homologue PIGF is arteriogenic. Evidence for a monocyte-mediated mechanism. Circ Res 2003;92:378-385.

32 Lutton A, Tjwa M, Moons L, et al: Revascularization of ischemic tissues by PlGF treatment, and inhibition of tumor angiogenesis, arthritis and atherosclerosis by anti-Flt 1 . Nat Med 2002;8:831-840.

33 Kamihata $H$, Matsubara $H$, Nishiue $T$, et al Improvement of collateral perfusion and regional function by implantation of peripheral blood mononuclear cells into ischemic hibernating myocardium. Arterioscler Thromb Vasc Biol 2002;22:1804-1810.

34 Iba O, Matsubara H, Nozawa Y, et al: Angiogenesis by implantation of peripheral blood mononuclear cells and platelets into ischemic limbs. Circulation 2002;106:2019-2025.

35 Huss R, Gatsios P, Graeve L, et al: Quiescence of CD34-negative hematopoietic stem cells is mediated by downregulation of Cyclin B and no STAT activation. Cytokine 2000;12:11951204

36 Jiang Y, Jahagirdar B, Reinhardt RE, et al: Pluripotency of mesenchymal stem cells derived from adult marrow. Nature 2002;418:41-49.

37 Harraz M, Jiao C, Hanlon HD, et al: CD34blood-derived human endothelial cell progenitors. Stem Cells 2001;19:304-312. 